\title{
Criterios prácticos de restauración arquitectónica a mediados del siglo XIX: la restauración de la iglesia románica de San Juan Ante Portam Latinam en Arroyo de la Encomienda (Valladolid)
}

\section{Practical criteria for architectural restoration in the mid- nineteenth century: the restoration of the Romanesque church of San Juan Ante Portam Latinam in Arroyo de la Encomienda (Valladolid)}

\author{
Francisco Javier Domínguez Burrieza \\ Universidad de Valladolid (España) \\ fjdominguez@fyl.uva.es
}

Fecha de recepción: 10/09/2018

Fecha de aceptación: 24/07/2019

\section{Resumen}

La restauración de la iglesia románica de San Juan Ante Portam Latinam, en Arroyo de la Encomienda (Valladolid), en 1876, refleja algunas de las ideas violletianas dominantes en la práctica restauradora española de la época, así como la aplicación de la Real Orden de 14 de septiembre de 1850. Se trata del trabajo más personal, en este campo, del reputado arquitecto Jerónimo Ortiz de Urbina Díaz de Junguitu. Perteneciente a las primeras promociones de la Escuela Especial de Arquitectura de Madrid, condiscípulo de Demetrio de los Ríos y Juan de Madrazo y amigo de Adolfo Fernández de Casanova, todos ellos arquitectos restauradores influidos por Viollet-le-Duc. A la vez que incluimos numerosa documentación inédita (expedientes de obras y libros de actas), resaltamos el valor de la fotografía en este tipo de trabajos, recuperando cuatro de ellas que se realizaron en el año 1867.

Palabras clave: Restauración arquitectónica; Arquitectura siglo XIX; Jerónimo Ortiz de Urbina; Viollet-le-Duc; Arquitectura románica; Valladolid (España).

\footnotetext{
Abstract

The restoration of the Romanesque church of San Juan Ante Portam Latinam, in Arroyo de la Encomienda (Valladolid), in 1876, reflects some of the dominant violletian ideas in Spanish restoration practice at the time, as well as the application of the Royal Order of 14 September 1850. This is the most personal work, in this field, of the renowned architect Jerónimo Ortiz de Urbina Díaz de Junguitu. He
} 
Criterios prácticos de restauración arquitectónica... - F.J. Domínguez Burrieza

belonged to the first graduating classes of the Special School of Architecture of Madrid, fellow student of Demetrio de los Ríos and Juan de Madrazo and friend of Adolfo Fernández de Casanova, all of them restoring architects influenced by Viollet - le - Duc. At the same time that we include numerous unpublished documentation (files of works and books of minutes), we highlight the value of photography in this type of work, recovering four of them that were carried out in 1867.

Keywords: Architectural restoration; 19th century architecture; Jerónimo Ortiz de Urbina; Viollet-le-Duc; Romanesque architecture; Valladolid (Spain)

\section{INTRODUCGIÓN}

La restauración de la iglesia románica de San Juan Ante Portam Latinam (fig. 1), en Arroyo de la Encomienda (Valladolid) ${ }^{1}$, fue el trabajo más personal, dentro de este campo, de Jerónimo Ortiz de Urbina Díaz de Junguitu (1824 - 1909)², el arquitecto de mayor relevancia en toda la provincia vallisoletana durante la segunda mitad del siglo XIX.Profesoren laAcademia deBellas Artes de la Purísima (desde 1852) y en laEscuela Libre de Maestros de Obras, Aparejadores, Agrimensores y Directores de Caminos Vecinales (desde 1869), en Valladolid, Ortiz de Urbina ejerció su papel docente ante un buen número de maestros de obras que durante la segunda mitad del siglo XIX y el primer tercio del XX desarrollaron su profesión en las actuales regiones de Castilla y León, Asturias, Galicia, Cantabria y País Vasco (Domínguez, 2013, pp. 37 y 38).

La fábrica de la iglesia se iniciaba en torno al año 1150, construyéndose a lo largo de la segunda mitad del siglo $\mathrm{XII}^{3}$. A todas luces, constituye uno de los ejemplos más interesantes del románico vallisoletano. De fundación templaria, el edificio se engloba, debido a sus características formales, dentro del románico rural de la zona oriental de la provincia: iglesia de pequeñas dimensiones, una sola nave cubierta de madera, ausencia de contrafuertes, zócalo de piedra, portada ubicada en la zona sur del templo y temas iconográficos similares a los del resto de edificios del grupo (Heras, 1966, p. 67). Pese a las importantes obras de restauración, que afectaron a

1 Hace unos años se publicó un sucinto estudio bibliográfico sobre el edificio (Olivera y Ruiz, 2002, pp. $103-112$ ).

2 Ortiz de Urbina fue el arquitecto nombrado desde un principio para llevar a cabo los trabajos en la iglesia de San Juan. En todo momento firmó como técnico la documentación generada en torno a la restauración del templo. Así, no fue su concuñado, el arquitecto Segundo de Rezola, el proyectista y director de las obras, tal y como se había pensado hasta ahora. El nombre de este último tan solo aparece junto al de Ortiz de Urbina una vez concluida la restauración. El nombramiento de Rezola como Arquitecto Diocesano, el 29 de noviembre de 1877 (Domínguez, 2010, pp. 226 y 227), justifica su inclusión en la memoria final enviada a la Comisión Provincial de Monumentos de Valladolid a finales de 1878, cuando los trabajos ya habían finalizado hacía algo más de dos años.

3 Ya la Sociedad Castellana de Excursiones aseguraba que la iglesia era del siglo XII (Iturralde, 1904, p. 365). Otros estudios mantuvieron la misma cronología (González, 1932 - 1933, p. 252; Heras, 1966, pp. 73 y 74). 


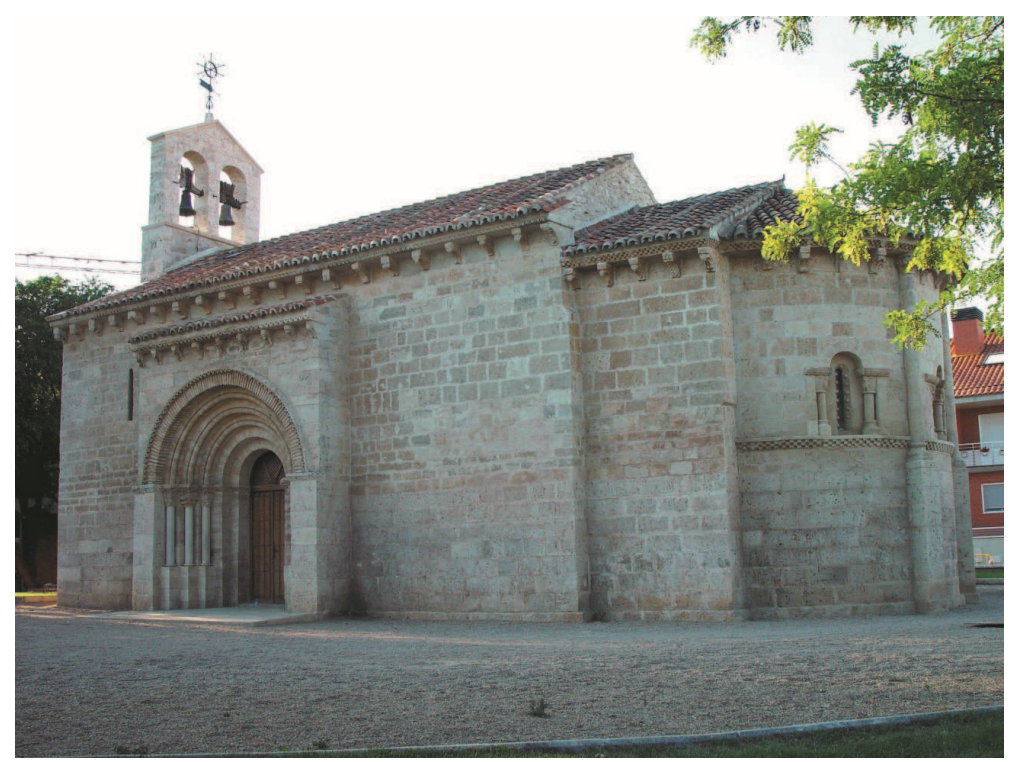

Figura 1. Iglesia de San Juan Ante Portam Latinam, en Arroyo de la Encomienda (Valladolid). Segunda mitad del siglo XII. Elaboración del autor.

la inclusión de un nuevo sistema abovedado y un cuerpo de sacristía independiente del de la iglesia, el resto de la fábrica, fundamentalmente su exterior, prácticamente se conservó intacto. Aun así, sin haber profundizado en el estudio de las obras de restauración que salvaron al templo de la ruina, algunos historiadores han criticado, duramente, lo ejecutado por Ortiz de Urbina ${ }^{4}$.

Hasta ahora, salvo la fecha, el nombre del arquitecto restaurador, al que se añadió, erróneamente, tal y como se demuestra a continuación, el de Segundo de Rezola, y algunos datos y consideraciones sobre la intervención, sin que se hubiesen sometido a análisis (Olivera y Ruiz, 2002, pp. 103 - 112), poco más se sabía en torno a la restauración de la iglesia de San Juan Ante Portam Latinam. El estudio se ha llevado a cabo tomando como base el expediente de reparación y restauración de la iglesia y la documentación generada en torno a la misma, conservada, fundamentalmente, en los archivos de la Real Academia de Bellas Artes de San Fernando, el Histórico Provincial de Valladolid y el de la Catedral de Valladolid.

Como veremos, aunque los trabajos de restauración no se adscriben totalmente al pensamiento de Viollet-le-Duc, sí se toma este como base, así como lo preceptuado por la Real Orden de 14 de septiembre de 1850 en cuestiones de restauración. A ello,

4 Felipe Heras concluyó que solo variaron "algunos rasgos estructurales", lo que permitió, según él, la conservación del "ejemplo más acabado y completo del románico oriental [de la provincia de Valladolid]" (Heras, 1966, p. 73). En este sentido, tampoco debemos obviar la acertada observación de Navascués, en la que afirma que "la historia de los edificios [...] no concluye con la terminación de las obras sino que, al contrario, comienza en aquel preciso instante” (Navascués, 1987, p. 387). 
debemos añadir algunos conceptos que, aun presentes en San Juan Ante Portam Latinam, serán desarrollados años después por Camilo Boito. Todavía lejos quedan las ideas sobre restauración propuestas por Luca Beltrami o Renato Bonelli, a principios y mediados del siglo XX, respectivamente.

\section{DESARROLLO DEL EXPEDIENTE DE REPARAGIÓN Y RESTAURACIÓN DE LA IGLESIA}

El 2 de septiembre de 1864, el Ayuntamiento de Arroyo (perteneciente a la Encomienda de Wamba, de ahí el actual nombre de Arroyo de la Encomienda) y su párroco informaban a la Junta Diocesana de Obras y Reparaciones de Valladolid del estado de ruina de la única iglesia de la localidad. El objetivo era que los trabajos de reparación necesarios se hiciesen con cargo a la partida de reparación de templos de aquella corporación. En la solicitud señalaban que durante el mes de agosto se había derrumbado parte del tejado del templo, afectando, sobre todo, a la zona del altar mayor. "Completamente abierto a la intemperie", para continuar oficiando se habilitó un altar cercano a la puerta principal. La restauración se tornaba urgentísima.

La Junta Diocesana aceptó la apertura del expediente, encargando, tal y como venía ocurriendo en aquellos trabajos que seguían dicha vía administrativa, que los solicitantes propusiesen un arquitecto que se hiciese cargo del proyecto. De esta forma, y posiblemente por su reputación y experiencia en la reparación y restauración de templos de la diócesis vallisoletana (Domínguez, 2013, pp. 37 - 66), Ortiz de Urbina fue el elegido por el pueblo de Arroyo, aceptándolo la Junta Diocesana en el mes de noviembre ${ }^{5}$. Meses más tarde, el 16 de junio de 1865, el arquitecto firmaba el informe sobre el estado del edificio, además del presupuesto y el pliego de condiciones de los trabajos de restauración ${ }^{6}$. Debía practicarse un recalce general, el arreglo de algunos muros desplomados, la reconstrucción de ciertos adornos ya "mutilados" y la recomposición de la cubierta. El mal estado de esta última se debía al gran peso de la espadaña, ajena al origen y estilo del edificio, que sin más descansaba sobre el arco del triunfo, es decir, donde "principia el presbiterio". La escalera que conducía a la espadaña era una ruina y en el interior también se debía sustituir el pavimento. Además, ante la ausencia de sacristía, se había "inutilizado el hueco de debajo del coro" para cumplir esta función.

El arquitecto presupuestó las obras en 42.163 reales $^{7}$; cantidad absolutamente desorbitada.

5 Archivo de la Catedral de Valladolid, Reparación de Templos y Conventos, Valladolid (ACVA, RTC), legajo 1837 - 1861, exp. 22, 4 de noviembre de 1854.

6 ACVA, RTC, legajo 1837 - 1861, exp. 22, 16 de junio de 1865.

7 Ibídem. 


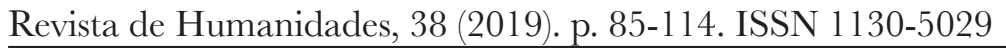

Pronto, el 27 de julio de 1865, el Gobernador de la Provincia daba el visto bueno al proyecto planteado por Ortiz de Urbina, y un mes más tarde la Junta Diocesana remitía el expediente al Ministerio de Gracia y Justicia ${ }^{8}$. En ese punto este se paralizó. Ante el silencio del Ministerio fue Ortiz de Urbina quien se ofreció a tratar de conseguir el apoyo tanto de la Real Academia de Bellas Artes de San Fernando como el de sus propios compañeros de la Comisión Provincial de Monumentos de Valladolid, que logró por unanimidad ${ }^{9}$. Sin embargo, años más tarde, en 1868, en una de las comunicaciones que la Comisión envió a la Academia de San Fernando, se afirmaba, amargamente, que desde mediados de 1865 los oficios divinos se estarían llevando a cabo, como ya había señalado Ortiz de Urbina, "en un lugar impropio y de malas condiciones". Se recordaba la mala conservación de la cubierta y la absoluta ruina del coro $^{10}$, al mismo tiempo que se insistía en el "mérito artístico que reunía la Capilla de Arroyo"11, de "estilo bizantino"12.

Ortiz de Urbina solicitó entonces que la Comisión se dirigiera al Gobernador, cuya intervención sería "una verdadera prueba de amor á las Bellas artes y un señalado

8 ACVA, RTC, legajo 1837 - 1861, exp. 22, 31 de agosto de 1865.

9 Desde fechas tempranas, la Comisión Provincial de Monumentos de Valladolid estuvo informada del desarrollo del expediente de restauración. Sin embargo, su intervención en el caso fue excepcional. Normalmente, dicha corporación no solía involucrarse en aquellos expedientes abiertos por la Junta Diocesana, pero en esta ocasión fue diferente. De hecho, fue la Comisión la que en repetidas ocasiones insistió en la decisiva restauración de la iglesia, incluso más que la propia Diócesis.

10 Archivo Histórico Provincial de Valladolid, Valladolid (AHPVA), Sección Histórica (SH), caja 269, legajo 5, exp. 9, 1 de abril de 1868.

11 AHPVA, Comisión de Monumentos (CPM), Libros de Actas (LA), sesión de 18 de noviembre de 1865 , fol. 46.

12 AHPVA, SH, caja 269, exp. 136, 18 de noviembre de 1865. Tachada de "maciza y ruda" en el siglo de las Luces (Calatrava, 1995, p. 60), la arquitectura románica fue conocida por los escritores románticos durante el siglo XIX con el término "romano - bizantina". No obstante, y como también hizo Ortiz de Urbina, en muchas ocasiones se abrevió el término utilizándose solo la palabra "bizantino", que a veces creó confusión con el arte desarrollado en Bizancio (Panadero, 1997, p. 252). Es más, este concepto tan general chocaba con las ideas positivistas que Juan Bautista Lázaro intentó divulgar, pocos años más tarde, a través de la creación de una cátedra de Restauración en la Escuela de Arquitectura de Madrid. La clasificación de los monumentos en tan solo "dos o tres que se tienen siempre a mano" lo consideraba absurdo y científicamente atrasado (Lázaro, 1884, pp. 193 y 194). Quadrado, común en su época, hizo uso de la misma terminología para el estilo Románico. Respecto a la iglesia de San Juan Ante Portam Latinam de Arroyo de la Encomienda concretaba, además, que si sobre este género buscaba "el artista una perfecta y bien conservada joya, no la encontrará sino en un pueblo de catorce chozas más bien que casas, á medio camino entre Simancas y Valladolid" (Quadrado, 1861, p. 180). Según la memoria de las labores realizadas por la Comisión Provincial de Monumentos hasta 1867, Ortiz de Urbina catalogó el estilo de la iglesia de "bizantino puro". Memoria de las labores realizadas por la Comisión de Monumentos Históricos y Artísticos de Valladolid desde si instalación hasta el 1 de octubre de 1867, Real Academia de Bellas Artes de San Fernando, Archivo-biblioteca, Madrid (RABASF), legajo 54-6/2. En este caso, Ortiz de Urbina siguió la terminología utilizada por Piferrer en Recuerdos y Bellezas de España y por Caveda en su Ensayo histórico sobre los diversos géneros de la Arquitectura empleados en España desde la dominación romana hasta nuestros días. Sobre este tema puede consultarse García, 1988, pp. 139 - 186. 
servicio al pueblo de Arroyo por ser la única Iglesia en dicho pueblo"13. La idea era archivar el expediente instruido el 31 de agosto pasado para que, posiblemente, la Comisión se encargase directamente de la gestión y así lograr del Ministerio de Fomento una partida presupuestaria. Queda claro que el pensamiento estaba puesto en el nuevo Reglamento de las Comisiones provinciales de monumentos históricos y artísticos, aprobado días más tarde, el 24 de noviembre de 1865. En todo caso, el llamamiento de Ortiz de Urbina no tuvo resultados positivos, ya que a principios de 1867 el arquitecto volvía a insistir sobre lo mismo. Fue entonces cuando el también arquitecto Antonio Iturralde propuso la completa reparación del edifico bajo el amparo de la Comisión que él mismo presidía. Sin embargo, la opinión de Iturralde no fue compartida por todos los miembros. Algunos de ellos veían en los trámites seguidos hasta el momento la vía más idónea ${ }^{14}$. De este modo, desde un principio pudo considerarse el caso de San Juan un obstáculo para la restauración de otros edificios de la ciudad de Valladolid, casos de las iglesias conventuales de San Benito y San Pablo o el antiguo colegio de San Gregorio ${ }^{15}$. Aun así, se acordó que la subcomisión nombrada para evitar el paso de los objetos artísticos e históricos del castillo de Portillo (Valladolid) "a manos extranjeras o incompetentes", compuesta por Iturralde, Pablo Gil, César Alba y Ortiz de Urbina, practicase también un reconocimiento a la iglesia de San Juan ${ }^{16}$. Con posterioridad, se daría cuenta a la Junta Diocesana, intentando conseguir, después, la mediación de la Academia de San Fernando.

La visita al templo demuestra cómo la fotografía comenzaba a ser un apoyo fundamental en los trabajos de la Comisión. Se tomaron cuatro instantáneas que definieron el estado exacto del edificio ${ }^{17}$. Lo mismo que poco tiempo antes habían llevado a cabo el arquitecto Domingo Rodríguez Sesmero y el pintor Agapito López de San Román con el Arco de Santiago, en Valladolid (Fernández, 1981, p. 165). Estos documentos gráficos, custodiados en el Archivo de la Real Academia de Bellas Artes de San Fernando, y de incuestionable valor, vuelven hoy a ver la luz.

Todo se desarrolló con lentitud. En noviembre, Ortiz de Urbina solo pudo informar a la Comisión de la realización de la visita al templo ${ }^{18}$. Nada nuevo se produjo hasta febrero de 1868, cuando el pintor José Martí y Monsó, amigo del

13 AHPVA, SH, caja 269, legajo 3, exp. 136, 18 de noviembre de 1965.

14 AHPVA, CPM, LA, sesión de 12 de enero de 1867, fol. 9.

15 Por extraño que pueda parecer, las cantidades asignadas por el Ministerio de Fomento para llevar a cabo obras de conservación y restauración en España no se otorgaron en los años 1867 y 1868 (Ordieres, 1995, p. 85).

16 AHPVA, CPM, LA, sesión de 12 de enero de 1867, fol. 9.

17 Ibídem. Se tomaron fotografías del conjunto arquitectónico, de la portada, del ábside y del detalle de uno de sus vanos. Memoria de las labores..., RABASF, legajo $54-6$ / 2. Las cuatro fotografías, remitidas a Gracia y Justicia el 9 de mayo de 1868, se hallan en RABASF, Fotografías, caja 27, exp. 287, fot. 2162 - 2165. Cuatro meses después, Gil presentaba a la Comisión las fotografías. AHPVA, CPM, LA, sesión de 18 de mayo de 1867, fol. 16v.

18 AHPVA, CPM, LA, sesión de 9 de noviembre de 1867, fol. 26. 


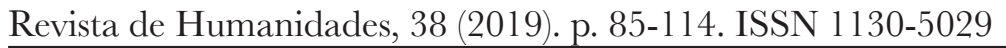

arquitecto, propuso, otra vez, que desde dicha corporación se impulsara el expediente. El primer paso sería el envío a la Academia de San Fernando de las fotografías que se habían tomado del templo, además de una copia del presupuesto de las obras formado, en su día, por Ortiz de Urbina. Con el propósito de lograr del Gobierno los fondos necesarios para la restauración, la Comisión, además, hizo hincapié en la conveniencia de la conservación del "único" ejemplo "que permanece en esta provincia de los Templarios"19.

El presupuesto de las obras se redujo a $4.218 \operatorname{escudos}^{20}$. Aún así, por miedo a una negativa, la Comisión prefirió suprimir varias obras nuevas que, en principio, se habían pensado llevar a cabo, concretándose en "la estricta reparación de lo que actualmente se conserva". Con el recorte se daba por hecho reunir la mitad de lo presupuestado. Esta suma permitiría reparar la cubierta, los embaldosados de la iglesia y el coro, reponer la puerta principal, varias ventanas y, finalmente, reformar la espadaña, cuyo excesivo peso ponía en serio peligro el edificio ${ }^{21}$. Como ya se había acordado meses atrás, la Academia recibió las fotografías que apoyaban el informe realizado por Ortiz de Urbina ${ }^{22}$.

Tan solo tres meses después, en mayo, se informaba a la Comisión de la aceptación del presupuesto por parte de la Academia y, por tanto, de la preceptiva solicitud elevada al Ministerio (De la Cámara, 1868, p. 30). Desde la Academia se alabó el gran mérito histórico y artístico del edificio demostrado por las cuatro fotografías. Además, con la "pequeña suma" solicitada, por fin la iglesia podría ser rehabilitada para el culto ${ }^{23}$.

El Gobierno de la Provincia, encargado de notificar el anterior acuerdo de la Academia a la Comisión, comunicó a esta última que, en lo sucesivo, debía informar de manera cabal sobre el asunto, ya que, con incredulidad, no entendían cómo no existía en sus dependencias ningún antecedente sobre el mismo ${ }^{24}$. La Comisión explicó que el hecho de no haber notificado al Gobernador la intención de reparar la iglesia había respondido solamente a que la Junta Diocesana, organismo que había instruido el expediente de reparación, había tratado, directamente, con el Ministerio de Gracia y Justicia ${ }^{25}$. La Comisión reconocía entonces que tan solo había tenido un "conocimiento extraoficial" del expediente (lógicamente, el proporcionado por Ortiz de Urbina) y que debido a su naturaleza solamente se había centrado en conseguir

\footnotetext{
19 AHPVA, CPM, L.A, sesión de 1 de febrero de 1868, fol. 36.

201 de abril de 1868, AHPVA, SH, caja 269, legajo 5, exp. 9, 1 de abril de 1868.

21 Ibídem.

22 Ibídem.

23 AHPVA, SH, caja 269, legajo 5, exp. 10, 11 de mayo de 1868.

24 Ibídem.

25 AHPVA, SH, caja 269, legajo 5, exp. 11, 29 de mayo de 1868.
} 
la aprobación de los trabajos ${ }^{26}$. Pocos días después, el Gobierno de la Provincia comunicaba a la Comisión sus contactos con la Junta Diocesana ${ }^{27}$.

Pese a que todo indicaba que la mediación de la Academia de San Fernando acabaría por otorgar la cantidad solicitada desde la Comisión, esto no fue así. La Comisión tenía la absoluta certeza de que el expediente había sido relegado al olvido $^{28}$. No obstante, aunque sin resultados satisfactorios, la Comisión no cejó en su empeño, e intentó, a través del Gobernador, que la Junta Diocesana se interesara, todavía más, en la finalización del expediente ${ }^{29}$. Transcurrido un tiempo, la Comisión se encargó de enviar urgentes misivas a cada una de las corporaciones con capacidad para resolver. Así, en diciembre de 1868, Iturralde proponía que se recordase a la Academia de San Fernando que la iglesia cada día presentaba un deterioro mayor ${ }^{30}$. Vuelta a empezar, en mayo de 1870 la Comisión se vio obligada a rebajar sus pretensiones económicas hasta tal punto que pensó en solicitar, en el caso de que no fuera posible la concesión de la mitad de lo presupuestado, al menos la cuarta parte ${ }^{31}$. En esta ocasión, los fondos se reclamaron al Ministerio de Fomento, esperando que en su presupuesto existiese una partida para conservación y reparación de monumentos históricos y $\operatorname{artísticos}^{32}$. Igualmente, se tuvo la intención de pedir autorización para que las obras se llevasen a cabo por administración ${ }^{33}$. Es decir, que en lugar de que la gestión corriese a cargo de diferentes contratas parciales, Ortiz de Urbina, como arquitecto restaurador, tendría un mayor control sobre los trabajos. Por tanto, la Comisión volvió a informar de su propuesta a la Academia, que requirió la elaboración de un informe y, "á ser posible", el envío de una nueva fotografía del edificio ${ }^{34}$. Sorprendentemente, a finales del mes de septiembre la Comisión decidía suspender cualquier resolución al respecto ${ }^{35}$, no generándose más noticias hasta tres años más tarde. Sin duda, el motivo lo encontramos en la difícil relación Iglesia - Estado entre 1868 y 1873, lo que ocasionó la paralización de muchos expedientes de restauración de edificios religiosos (González - Varas, 1996, p. 105). El 28 de septiembre de 1873 se volvía a mencionar el estado de abandono y casi ruinoso de la iglesia. Como si nada hubiera pasado y con la completa seguridad de que no existían órdenes ni directrices a seguir emitidas desde Madrid, la Comisión transmitió su interés, otra vez, a la Academia de San Fernando ${ }^{36}$.

26 Ibídem.

27 AHPVA, SH, caja 269, legajo 5, exp. 12, 6 de junio de 1868.

28 AHPVA, SH, caja 269, legajo 5, exp. 7, 15 de junio de 1870.

29 AHPVA, CPM, LA, sesiones de 30 de mayo y de 13 de junio de 1868 , fol. 52r y 53r.

30 AHPVA, CPM, LA, sesión de 19 de diciembre de 1868, fols. 71v. y 72r.

31 AHPVA, CPM, LA, sesión de 28 de mayo de 1870, fol. 91v.

32 AHPVA, SH, caja 269, legajo 5, exp. 7, 15 de junio de 1870.

33 Ibídem.

34 AHPVA, SH, caja 269, legajo 5, exp. 8, 28 de junio de 1870.

35 La falta de vocales en la sesión obligó a tomar esta decisión. CPM, LA, sesión de 28 de septiembre de 1870 , fol. $94 \mathrm{r}$.

36 AHPVA, CPM, LA, sesión de 28 de septiembre de 1873, fols. 107v. y 108r. 


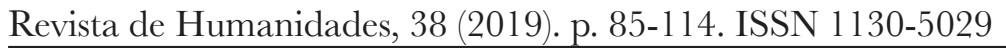

El 31 de marzo de 1875 el Subsecretario del Ministerio de Gracia y Justicia respondía a lo instruido diez años atrás. Este paso se convirtió en la primera evolución positiva del expediente desde el 31 de agosto de 1865, cuando la Junta Diocesana había solicitado contestación sobre el mismo al Ministerio. En su comunicación, Gracia y Justicia exigía que Ortiz de Urbina realizase un nuevo reconocimiento a la iglesia para determinar si con el antiguo presupuesto podía solventarse la restauración del templo o si, en su defecto, haría falta modificarlo debido al largo tiempo transcurrido ${ }^{37}$. Así se hizo, y el 2 de junio de 1875 se remitía al Ministerio un nuevo presupuesto que incluía novedades. La más destacada se centraba en la instalación "de una ligera bóveda en carácter con el edificio en sustitución de la cubierta pintada, quedando esta como una cubierta ordinaria" ${ }^{38}$. Por tanto, y como veremos a continuación, Ortiz de Urbina asimilaba entonces, y erróneamente, estilo Románico con sistema abovedado, buscando devolver al edificio su unidad, tal y como defendió Viollet-le-Duc, así como restaurarlo siguiendo el hipotético estilo que le era propio (Viollet, 1866, p. 24). Además, nuevamente se insistía ahora en la construcción de una sacristía en parte del viejo camposanto ${ }^{39}$.

En esta ocasión, todo transcurrió sin demora. Ortiz de Urbina indicó a la Comisión cómo "por Real Orden de 5 de julio siguiente, se mandó insertar el anuncio de la subasta que se verificó en 17 de Septiembre de 1875 y fue aprobada por la Superioridad en 15 de Octubre inmediato" ${ }^{40}$.

Aunque el plazo de ejecución era de seis meses, los trabajos se prolongaron casi un año. Si a finales de diciembre se comunicaba que se había "dado principio al acopio de la piedra necesaria para dichas obras el trece del actual" ${ }^{41}$, el 4 de noviembre

37 ACVA, RTC, legajo 1837 - 1861, exp. 22, 31 de marzo de 1875.

38 ACVA, RTC, legajo 1837 - 1861, exp. 22, 2 de junio de 1875.

39 ACVA, RTC, legajo 1837 - 1861, exp. 22, 2 de junio de 1875.

40 AHPVA, SH, caja 269, legajo 6, exp. 166, 12 de diciembre de 1878. A la subasta se presentaron José Pérez Escudero y Cayetano Orne (administrador del Conde de Guaqui), siendo este último al que finalmente se adjudicaron las obras. ACVA, RTC, legajo 1837 - 1861, exp. 22, 17 de septiembre de 1875 . Antes, a principios de agosto, Ortiz de Urbina había presentado unas condiciones adicionales a aquella Real Orden de 5 de julio de 1875 (ACVA, RTC, legajo 1837 - 1861, exp. 22, 5 de julio de 1875) que daba permiso a la publicación del anuncio de la subasta de las obras (finalmente el anuncio se publicó en el Boletín Oficial de la Provincia de 5 de septiembre). En estas, Ortiz de Urbina advertía que los trabajos debían llevarse a cabo en seis meses, a contar "desde los ocho días en que se le comunique la orden al contratista para dar principio á su ejecución”. Además, el arquitecto sería quien estimara y obligase al contratista a tener en obra el número de obreros necesario, con lo que se tomaba, así, una interesante medida para garantizar el éxito de los trabajos. ACVA, RTC, legajo 1837 - 1861, exp. 22, 7 de agosto de 1875 .

41 ACVA, RTC, legajo 1837 - 1861, exp. 22, 30 de diciembre de 1875. A mediados de mayo de 1876 se cumplió con el primer plazo de pago según lo dispuesto por la base $17^{\text {a }}$ de las condiciones aprobadas por la Real Orden de 5 de julio de 1875 (las obras fueron reconocidas por Ortiz de Urbina). ACVA, RTC, legajo 1837 - 1861, exp. 22, 11 y 22 de mayo de 1876. 
de 1876 ya se daban estas, oficialmente, por concluidas ${ }^{42}$. Con ello, el 11 del mismo mes se celebró una solemne inauguración ${ }^{43}$, aunque la recepción oficial y definitiva, según afirmó Ortiz de Urbina, tuvo lugar durante el segundo semestre de $1877^{44}$. Dos años después, en 1879, Ortiz de Urbina era nombrado Académico correspondiente de la Real Academia de Bellas Artes de San Fernando. En su candidatura, los profesores y reconocidos arquitectos de aquella academia, Simeón Ávalos y Antonio Ruiz de Salces, no dudaron en destacar de él la realización y ejecución de numerosos e importantes proyectos de conservación de templos (Domínguez, 2010, p. 37).

\section{LOS TRABAJOS DE RESTAURACIÓN}

Antes de la recepción de las obras, José Martí y Monsó propuso a la Comisión que los arquitectos encargados de la restauración facilitasen un informe de lo que se había ejecutado ${ }^{45}$. Pese a que hablaba en plural, Martí y Monsó no habría querido dejar escapar la oportunidad de alabar el buen trabajo realizado por el arquitecto. Pero, ¿a qué técnico se refería? Sin duda, a su amigo Ortiz de Urbina ${ }^{46}$ y no a Segundo de Rezola, arquitecto diocesano y cuyo nombre, por primera vez, aparecía en la documentación. Este es el motivo por el cual hasta ahora se pensaba que fue Rezola y no Ortiz de Urbina el arquitecto restaurador. Con cierto retraso, el 12 de diciembre de 1878, ambos arquitectos firmaban el informe ${ }^{47}$. Gracias a él sabemos con exactitud las obras que se practicaron en la iglesia y que a continuación analizamos.

42 En esta fecha así lo comunicaba el contratista, admitiendo que por el estado de deterioro de la iglesia había sido preciso realizar alguna que otra obra más de lo proyectado en un principio. ACVA, RTC, legajo 1837 - 1861, exp. 22, 4 de noviembre de 1876. De hecho, en la inspección que efectuaba, posteriormente, Ortiz de Urbina, se reconocía que estas obras añadidas habían sido de absoluta necesidad para la seguridad de la iglesia. ACVA, RTC, legajo 1837 - 1861, exp. 22, 8 de noviembre de 1876. También se llevaron a cabo otras para establecer el culto en la iglesia, como insistió en varias ocasiones el contratista., ACVA, RTC, legajo 1837-1861, exp. 22, 21 de febrero, 28 de mayo y 7 de diciembre de 1877.

43 La descripción de la celebración del acto religioso la encontramos en ACVA, RTC, legajo 1837 - 1861, exp. 22, 11 de noviembre de 1876.

44 AHPVA, SH, caja 269, legajo 6, exp. 166, 12 de diciembre de 1878.

45 Al mismo tiempo, con dicho documento se aprovechaba para que se reconociera a la Comisión el "lisonjero resultado" que habían tenido sus gestiones. AHPVA, CPM, LA, sesión de 14 de marzo de 1877, fol. 127.

46 La amistad entre Ortiz de Urbina y Martí y Monsó se ha demostrado en varias ocasiones (Ortega, 2000, p. 25).

47 El informe redactado por Ortiz de Urbina y Rezola se encuentra en AHPVA, SH, caja 269, legajo 6, exp. 166. Este fue aprobado por la Academia de San Fernando solo un mes más tarde. RABASF, LA, Sección de Arquitectura, sesión de 25 de enero de 1879, fol. 214r. - también fue enviada una copia a la Real Academia de la Historia. AHPVA, CPM, LA, sesión de 14 de diciembre de 1878; AHPVA, SH, caja 269, legajo 6, exp. 167, 16 de diciembre de 1878; Oficio en el que se informa sobre las obras de restauración de la iglesia parroquial de la villa de Arroyo, en Archivo del Gabinete de Antigüedades de la Real Academia de la Historia, Madrid (AGARAH), CAVA/9/7978/09(1) -. Ortiz de Urbina evacuó otro informe final que se adjuntó al expediente formado y tutelado por la Junta Diocesana. ACVA, RTC, legajo 1837 - 1861, exp. 22, 27 de abril de 1878. Junto a esta memoria de 


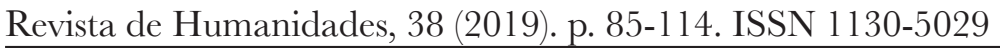

La Academia de San Fernando, por su parte y a través de la Comisión Provincial de Monumentos, felicitó la labor desarrollada por los arquitectos restauradores ${ }^{48}$, expresando, igualmente, su agradecimiento al Conde de Guaqui, propietario de la finca donde se ubicaba la iglesia ${ }^{49}$.

Probablemente, para los trabajos de restauración no se levantaron planos. Así, el Inventario artístico de Valladolid y su provincia (1970) informa, sin dar más explicaciones, de la existencia de algunos documentos gráficos relativos a la iglesia (Martín, 1970, p. 80). Sin embargo, entendemos que estos corresponden a los trabajos realizados por el Seminario de Estudios de Arte y Arqueología de la Universidad de Valladolid en la visita al templo durante el curso de 1932 - 1933 (Pérez, 1932 1933, p. 13). Dichos planos, publicados en un principio por González Tejerina y luego retomados por Heras García, se centran en la planta del edificio, en la que se diferencian las partes originales de lo reconstruido por Ortiz de Urbina (fig. 2).

En el último informe solicitado por Martí y Monsó, Ortiz de Urbina manifestaba que el estado de conservación de la iglesia, antes de ser intervenida, sería de "completa ruina" ${ }^{50}$. En él se indicaba cómo se había reconstruido el tercio inferior de los muros perimetrales del edificio. En parte de ellos se habían introducido nuevos cimientos, al mismo tiempo que se había utilizado para la reconstrucción sillería dura, limpia de coqueras y bien escuadrada (con sillares de heterogéneo tamaño) en lugar de la franca utilizada antiguamente ${ }^{51}$. Ortiz de Urbina analizaba

los trabajos realizados, también Ortiz de Urbina presentó la cubicación de las obras hechas para su liquidación y la valoración de las mismas, todo ello confeccionado con minucioso detalle.

48 Otra vez, esta felicitación podría dar pie a pensar que Ortiz de Urbina quizá compartiese con Rezola el trabajo en Arroyo. Nada más lejos de la realidad, ya que el nombre de Rezola no aparece en la documentación hasta la firma del informe de 12 de diciembre de 1878. En todo caso, sí es cierto que a ambos arquitectos les unió una gran amistad. Concuñados y tras el fallecimiento de Rezola, el 26 de octubre de 1879, Ortiz de Urbina fue el encargado de comunicar la noticia, oficialmente, a la Comisión Provincial de Monumentos. AHPVA, SH, caja 269, legajo 6, exp. 194, 30 de octubre de 1879; AHPVA, CPM, LA, sesión de 18 de noviembre de 1879, fol. 10r. Como integrante del cuerpo de profesores de la Escuela de Bellas Artes de la ciudad, también en el Ayuntamiento se sintió "la pérdida de tan celoso y distinguido Profesor". Archivo Municipal de Valladolid, Valladolid (AMVA), LA, sesión de 31 de octubre de 1879, fol. 366v. Su viuda, María del Rosario Cardán, señalaba entonces un dato revelador del que hasta hoy no se tenía noticia. Rezola se había encargado, mientras desempeñó el cargo de Arquitecto Municipal Interino (posiblemente durante parte de la primavera y verano de 1877), de la elaboración de unos planos de un mercado municipal que debía emplazarse en la plazuela de Portugalete, hecho de gran relevancia para la historia de la arquitectura vallisoletana. AMVA, Chancillería, caja 314, exp. 7; AMVA, LA, sesiones de 19 de marzo y 14 de mayo de 1880, fols. 109 y 173.

49 AHPVA, SH, caja 269, legajo 7, exp. 30, 28 de enero de 1879; AHPVA, SH, caja 269, legajo 6, exp. 173bis, 6 de febrero de 1879. La Comisión acordó realizar una copia de dicha comunicación para cada uno de los mencionados. AHPVA, CPM, LA, sesión de 1 de febrero de 1879, fol. 8v. Por otra parte, el Conde de Guaqui no solo sería propietario de la iglesia, sino de la mayor parte del pueblo de Arroyo (Ortega, 1895, p. 177).

50 AHPVA, SH, caja 269, legajo 6, exp. 166, 12 de diciembre de 1878.

$51 \mathrm{Al}$ analizar la intervención de Ortiz de Urbina nos ceñimos al informe que este y Rezola firmaron el 12 de diciembre de 1878 y a las condiciones facultativas que el primero había rubricado el 


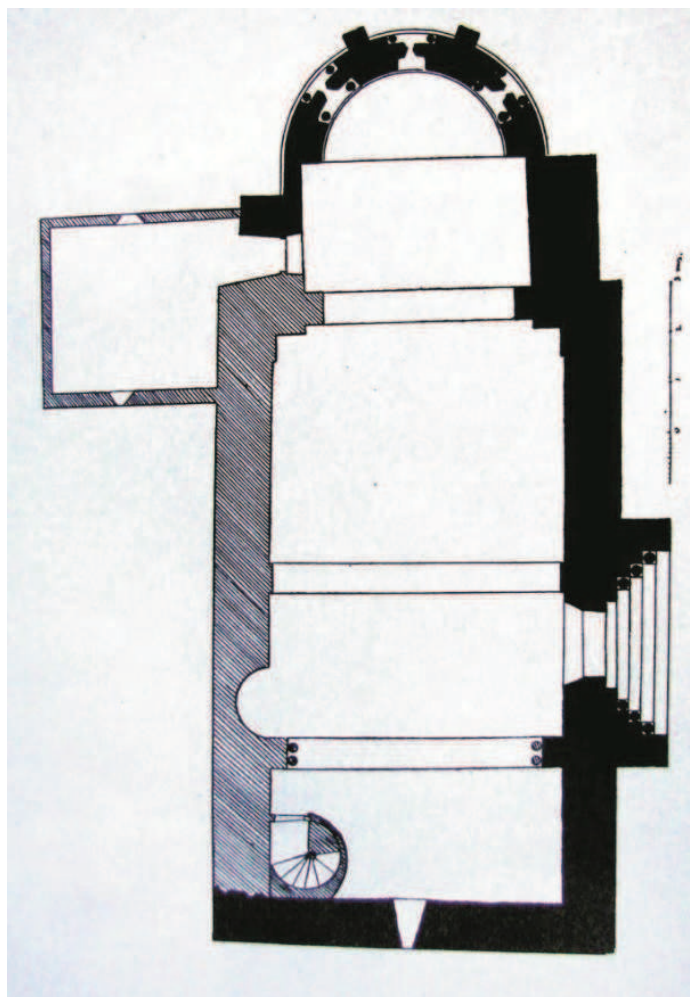

Figura 2. Planta de la iglesia en 1932. Dibujo publicado en González, 1932 - 1933.

por qué no se había empleado un material más consistente en aquella parte de la iglesia y llegaba a la conclusión de que la inexistencia de canteras cercanas habría condicionado la utilización de un material, en este caso, mucho más débil. Como vemos, una intervención que se oponía a lo defendido por John Ruskin en cuanto a la renovación material de los monumentos. En Arroyo, aunque unidas, la "forma" sería más importante que la "materia", en línea con lo que poco tiempo después veremos, con más decisión, y a otra escala, en Demetrio de los Ríos, condiscípulo de Ortiz de Urbina en la Escuela Especial de Arquitectura, y en Enrique María Repullés y Vargas (De los Ríos, 1895, pp. 8 y 9; González - Varas, 1993, pp. 301-307; 1994, p. 113; 1996, p. 62). El material, así, permitía a Ortiz de Urbina mejorar el edificio románico. Esta idea, presente en Viollet, se complementa con la búsqueda de la unidad de estilo que veremos más adelante con la inclusión de una bóveda de cañón que acabó sustituyendo a la techumbre de madera original. Al mismo tiempo, y pese a no pretender cumplir con este objetivo, el trabajo de Ortiz de Urbina evidenció el carácter actual de las nuevas adiciones preservando la autenticidad del monumento

2 de junio de 1875. De nuevo, respecto al tipo de piedra Ortiz de Urbina indicaba que debía ser de una clase similar a la de Villanubla. ACVA, RTC, legajo 1837 - 1861, exp. 22, 2 de junio de 1875. 
Revista de Humanidades, 38 (2019). p. 85-114. ISSN $1130-5029$

como documento. Esto mismo se relaciona, claramente, con lo que años después defendería Camilo Boito.

Se reconstruyeron, igualmente, los muros que cegaban los dos arcos formeros presentes en el lado norte de la iglesia ${ }^{52}$, desde los cimientos hasta la línea de cornisa, y que, tal vez, correspondían a una antigua y frustrada ampliación. Estos, según Ortiz de Urbina, se encontraban "enteramente desplomados" 53 , e incluso se hallaban ocultos tras unas escaleras en ruina que también acabaron por desmontarse ${ }^{54}$ (fig. 3).

En este sentido, a través de una de las fotografías que en 1867 se tomaron del edificio y que se remitieron tanto a la Real Academia de Bellas Artes de San Fernando como al Ministerio de Gracia y Justicia (figs. 4 - 7), en ese muro norte, justo en el

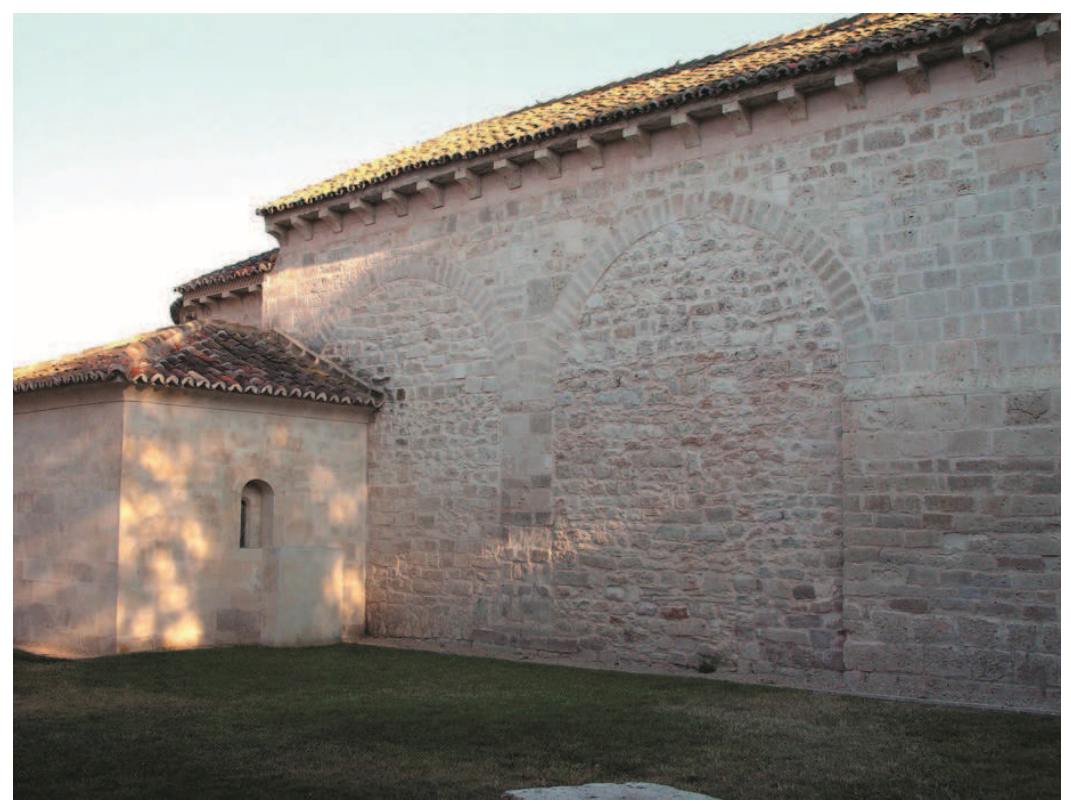

Figura 3. Estado actual de los arcos cegados del lienzo norte de la iglesia, junto a la nueva sacristía. Elaboración del autor.

52 González Tejerina ya daba cuenta de ello, señalando que el aparejo interior estaría recubierto de yeso. Además, incluía la planta del edificio, distinguiéndose, a través de su estudio, las partes correspondientes a la restauración de Ortiz de Urbina de la construcción original (González, 1932 1933, pp. 248 y 249). En este sentido, Heras García incluye también la bóveda de cañón de la nave (Heras, 1966, p. 67). La anterior planta, como el estudio de González Tejerina, tendrían su origen en la ya citada excursión organizada por el Seminario de Estudios de Arte y Arqueología de la Universidad de Valladolid.

53 AHPVA, SH, caja 269, legajo 6, exp. 166, 12 de diciembre de 1878.

54 ACVA, RTC, legajo 1837 - 1861, exp. 22, 27 de abril de 1878. 
mismo sitio donde años más tarde Ortiz de Urbina levantó la nueva sacristía, existía una construcción de ladrillo que incluso servía de apoyo a la antigua espadaña que hasta hoy tan solo conocíamos a través de la litografía de Isla $(1861)^{55}$, incluida en la obra de Quadrado y Parcerisa, Recuerdos y Bellezas de España (Fig. 8).

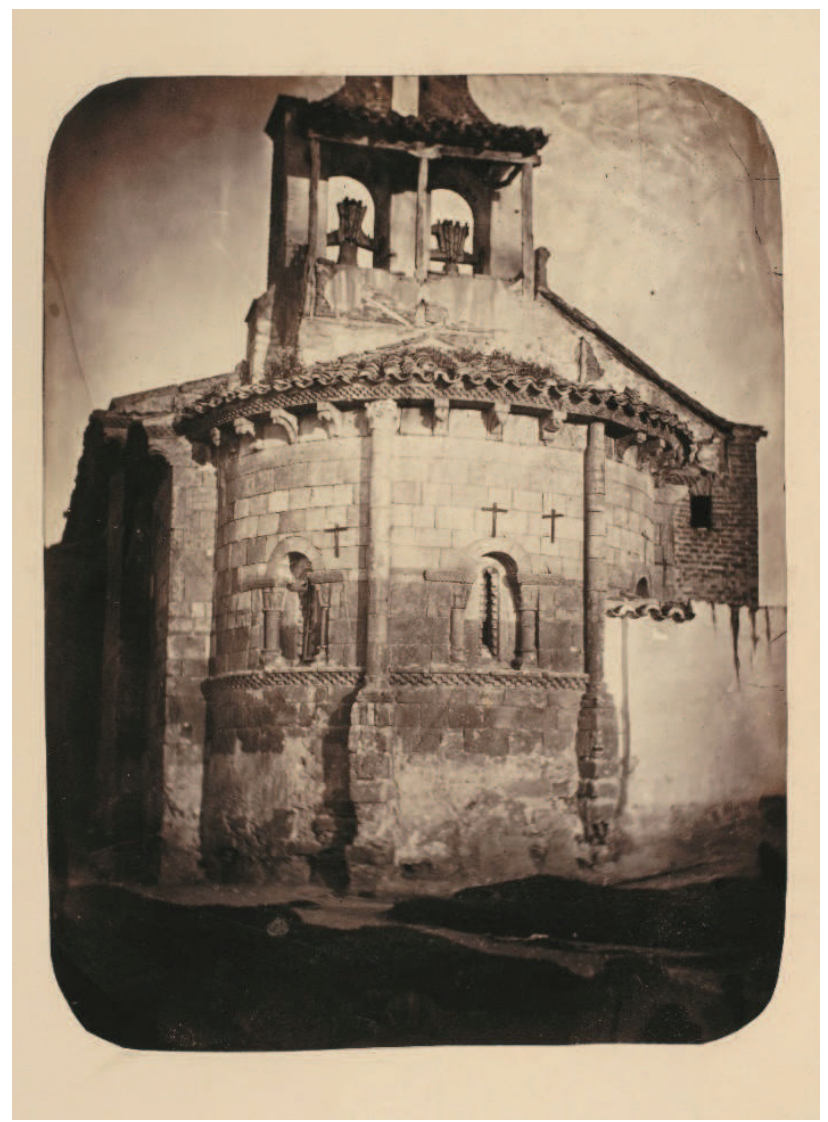

Figura 4. Estado del ábside, espadaña y construcción de ladrillo adosada al lado norte antes de la restauración de la iglesia. 1868. RABASF, Archivo-biblioteca, Fotografias, caja 27, exp. 287, fot. 2162.

55 A la hora de comparar las fotografías y el grabado de Isla (según el dibujo realizado por Parcerisa) puede comprobarse la veracidad arquitectónica en este último trabajo, algo que se ha atribuido a la obra en general (Ordieres, 1995, p. 106). 


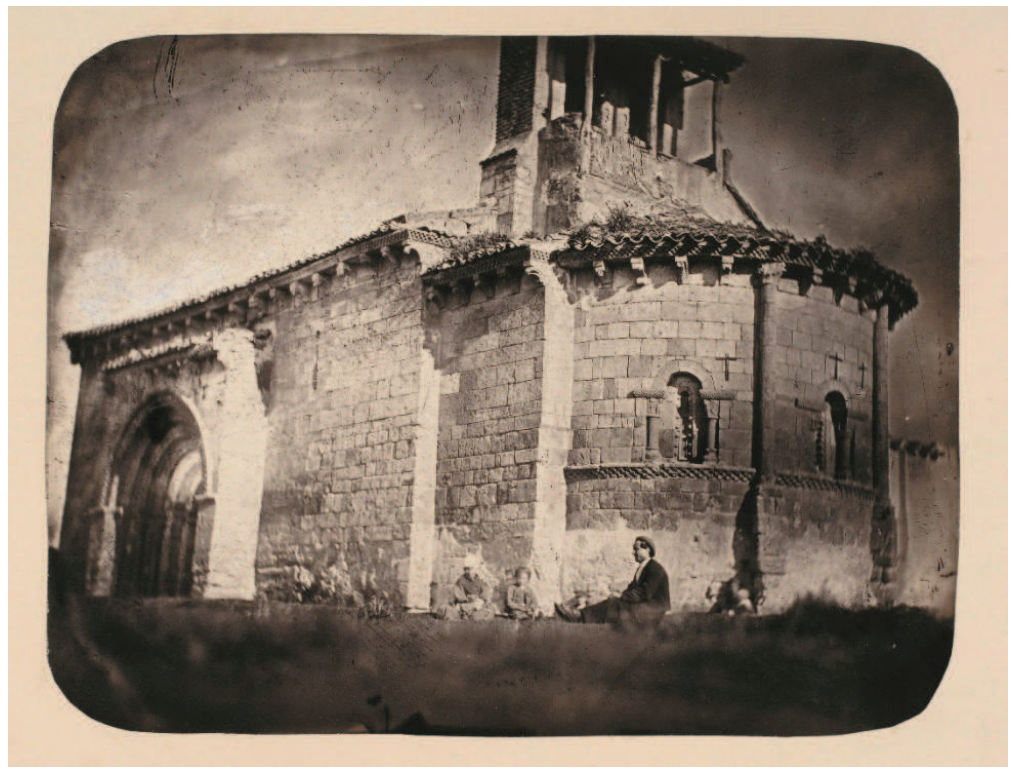

Figura 5. Vista general del estado de la iglesia antes de su restauración. 1868. RABASF, Archivo-biblioteca, Fotografias, caja 27, exp. 287, fot. 2163.

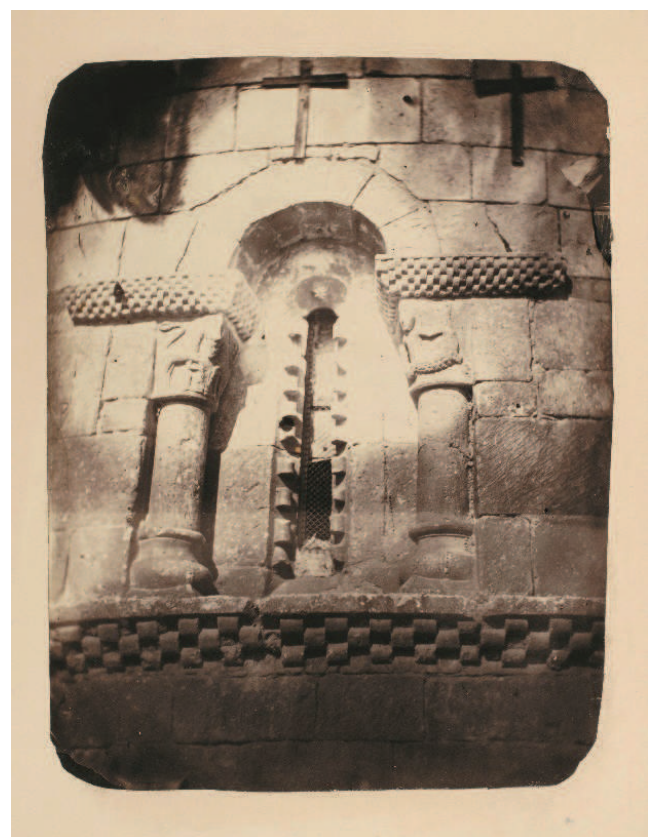

Figura 6. Estado de la portada de la iglesia antes de su restauración. 1868. RABASF, Archivo-biblioteca, Fotografías, caja 27, exp. 287, fot. 2164.

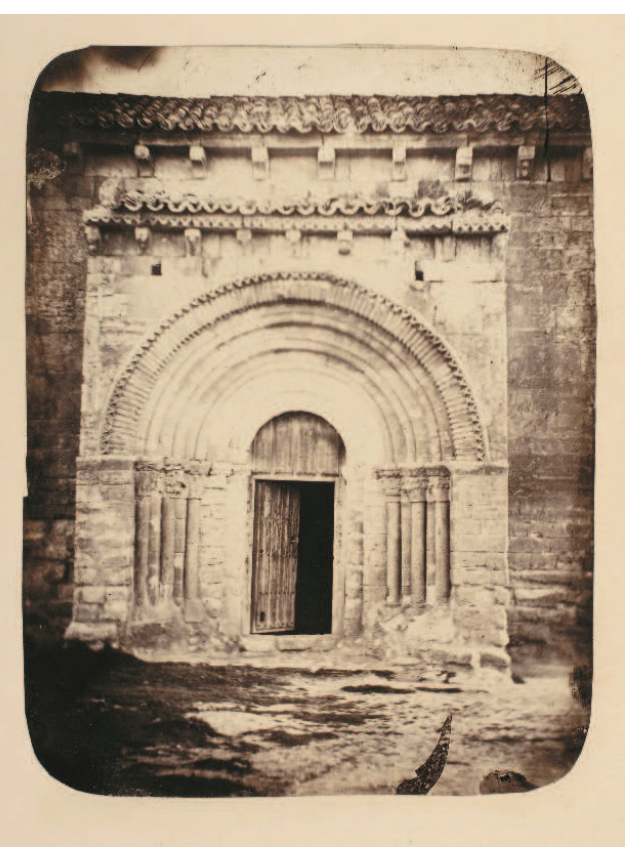

Figura 7. Estado de una de las ventanas delábside de la iglesia antes de su restauración. 1868. RABASF, Archivo-biblioteca, Fotografías, caja 27, exp. 287, fot. 2165. 


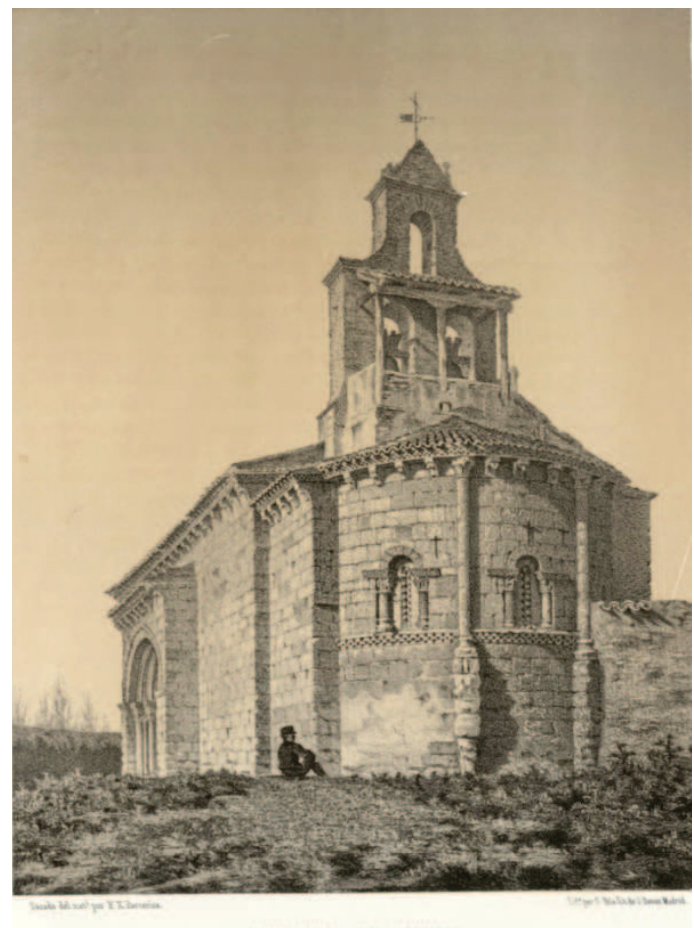

Figura 8. Litografía sobre la iglesia. 1861. Publicada en Quadrado, 1861, 184.

Las reconstrucciones murales se extendieron también al lado sur, haciéndose lo propio con otro lienzo, por su cara externa, contiguo a la puerta de entrada. De hecho, según el informe, los sillares de esta parte del edificio se encontraban "desunidos y sin enlace" $"$. En este caso, y según las fotografías tomadas en la excursión de 1932, se habría utilizado cemento para corregir la desunión y el deterioro del material en buena parte del resto de los muros (fig. 9). Desgraciadamente, un ejemplo de lo que Ríos denominó "teoría de los parches y emplastos" (De los Ríos, 1895, pp. 155-159). A través de estas mismas fotografías comprobamos cómo Ortiz de Urbina habría aplicado, debido a la exigencia aparente del material, y de manera inconsciente, el recurso diferenciador entre lo nuevo y lo antiguo, una de las premisas del modelo de restauración que defendería poco tiempo después Camilo Boito en el III Congreso de Ingenieros y Arquitectos italianos (1883). De esta forma, lo importante era salvar el edificio y pretender su máxima durabilidad, desprendiéndose, lo menos posible, de las características originales de la fábrica.

Respecto a la portada, ubicada en la fachada sur, Ortiz de Urbina reconocía la reconstrucción de resaltes y la inclusión de "columnitas nuevas", limitándose esto

56 AHPVA, SH, caja 269, legajo 6, exp. 166, 12 de diciembre de 1878. 


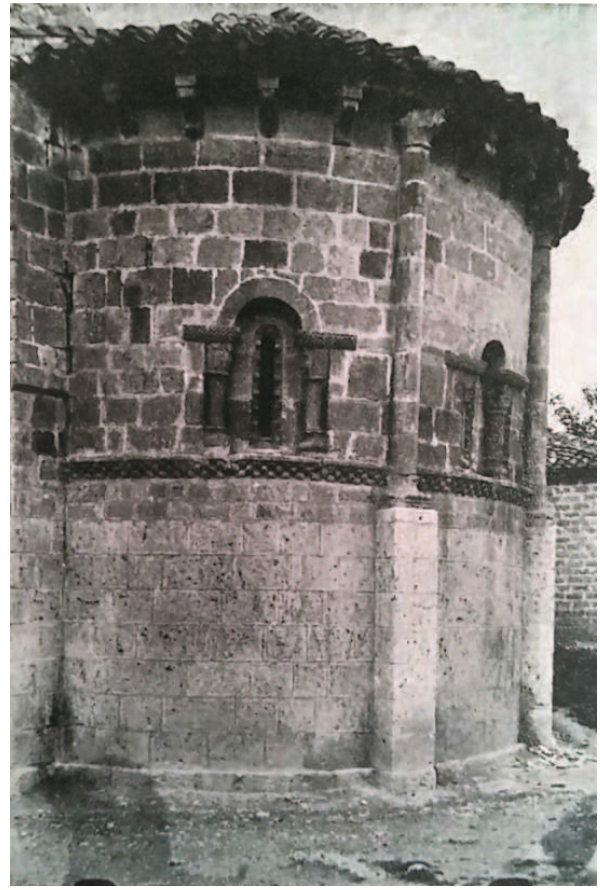

Figura 9. Exterior del ábside en 1932. Fotografía publicada en González, $1932-1933$.

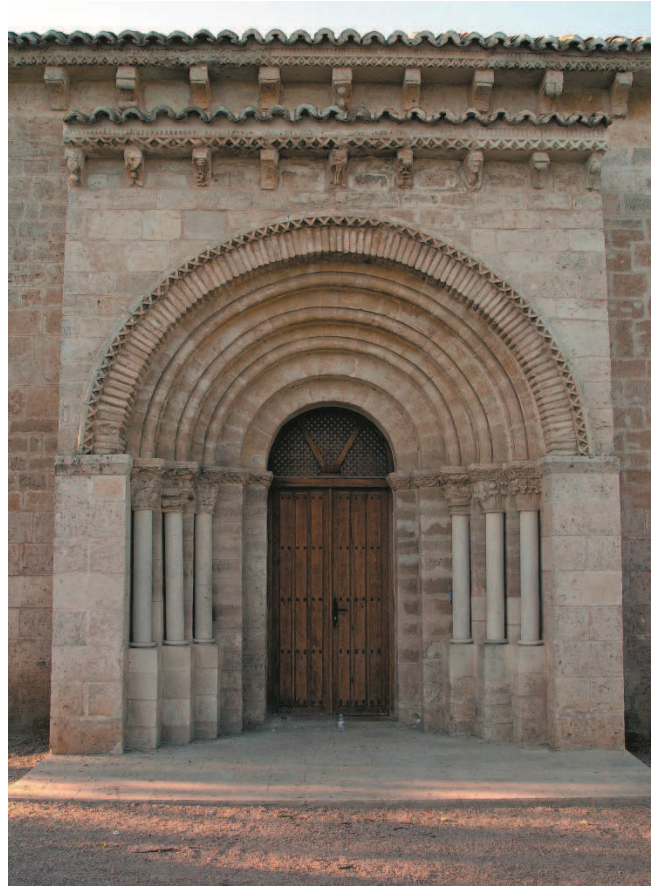

Figura 10. Estado actual de la portada de la iglesia. Elaboración del autor.

último, con total probabilidad, a la sustitución de los fustes ${ }^{57}$. Hoy día, tampoco conservamos los fustes de la restauración de 1876, eliminados con la llevada a cabo en 1995. En su lugar lucen otros monolíticos que, junto a las basas actuales (las anteriores eran de plinto alto y prismático), en cierto modo mudaron su imagen respecto a lo original (fig. 10).

El informe indica también cómo se habrían "restaurado algunos detalles", no precisando cuáles. Según las ya citadas fotografías tomadas en 1867, parece obvio que estos no correspondieron a la arquivolta exterior, trasdosada con una chambrana de cabezas de clavo y decorada con dovelas trabajadas al modo del almohadillado egipcio, sino al tejaroz, en relación al menos a uno de sus canes, y, sobre todo, al alero del tejado. Sorprendentemente, en 1895, Ortega y Rubio indicaba que la decoración de las arquivoltas habría desaparecido, entre otras causas, por la restauración (Ortega, 1895, p. 177). La fotografía lo desmiente. Además, Ortiz de Urbina declaró que siempre procuró conservar "las mismas formas y detalles que existían para no desmerecer, en nada, su importancia bajo el punto de vista artístico é histórico".

57 La Guía - Anuario de Valladolid de 1922 indicaba que el ábside estaría "perfectamente conservado y respetado en una reciente restauración" (Cossío, 1922, p. 166). 
Por tanto, la desaparición de decoración aquí no habría tenido sentido. De haberse conservado restos de decoración en el tiempo de la restauración, Ortiz de Urbina, sin duda, habría intentado su recuperación, sin practicar reinvención alguna. Es más, a la hora de incluir algunos canes nuevos, como el segundo del tejaroz, según se mira a la portada, el arquitecto copió un sencillo diseño geométrico que ya existía y se repetía alrededor del edificio de entre los también vegetales y figurados del templo. Lo mismo realizó con el resto de ménsulas. Así, Ortiz de Urbina se acercaba a la idea de "proyectos de restauraciones parciales" que poco tiempo después definieron Juan de Madrazo y Demetrio de los Ríos en León (González - Varas, 1993, pp. 294-300).

El exterior del edificio también incluyó un nuevo capite $1^{58}$. Este corresponde a una de las columnas adosadas que dividen el tambor absidal, en el lado del evangelio, y que destaca por la menor carnosidad de las hojas de palma, en relación con el otro original, y la esbeltez de las mismas. Su estética es claramente decimonónica. Es más, en una de las fotografías de 1867 apreciamos cómo la correspondiente columna adosada no poseía capitel. De la misma manera, también se incluyeron, según el informe, nuevas lacerías, siempre siguiendo el mismo carácter que las originales, además de nuevas ménsulas o canes. En este caso, Ortiz de Urbina sí desvirtuó la decoración del alero, puesto que lo que se aprecia a través de las fotografías antiguas es la repetición del mismo diseño de moldura taqueada que se conservó en el exterior del ábside y no la copia, al menos en todo el muro sur, de la ornamentación de cabezas de clavo o estrellas de cuatro puntas con bolas o perlas intercaladas que sí se hallaba presente en la arquivolta exterior de la portada y en el tejaroz. Con todo, el arquitecto se basó en las pistas dadas por el propio monumento y no, como ya en el siglo XX Luca Beltrami, en otro tipo de fuentes disponibles (dibujos, planos, etc). En este caso, no existe una seria investigación histórica sobre el edificio y sí un apoyo en la lógica intrínseca del mismo a la hora de restaurar y reparar algunas de sus zonas. Con ello, de nuevo, nos acercamos a ideas violletianas.

Uno de los aspectos más polémicos, además de lo relacionado con el sistema de cubrición de la iglesia, es el concerniente a la espadaña. Esta, no contemporánea a la construcción de la iglesia, se ubicó sobre el presbiterio. Ortiz de Urbina, "por el efecto y para la seguridad", sustituyó la antigua de ladrillo por una de piedra, en relación con el material empleado en todo el conjunto, ahora como prolongación del imafronte. Podría haberse conservado el uso del ladrillo, material más ligero, y mantener la misma ubicación, en el presbiterio. Sin embargo, los cambios introducidos por Ortiz de Urbina fueron más adecuados desde el punto de vista de la "restauración en estilo". Aun siendo la antigua espadaña de ladrillo, su excesivo peso había puesto en serio peligro la conservación del edificio. Las soluciones pudieron ser diversas, pero la menos costosa, y sin duda la más fiable para Ortiz de Urbina, fue la reubicación de la

58 Según Heras García, los capiteles del exterior del ábside habrían sido rehechos, asegurándolo, al menos, para uno de ellos (Heras, 1966, p. 68). Por desgracia, Herrero Marcos no analiza, como sí en los demás, estos capiteles (Herrero, 1997, pp. 128 - 139). 


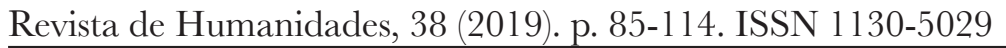

espadaña. Su nuevo emplazamiento posibilitaba el empleo de la piedra, unificándose así, material y visualmente, con la fábrica de la iglesia. La espadaña no constituía un elemento original del templo, sino que era un añadido que, según el arquitecto, ocasionaba graves problemas al edificio. La nueva, más sencilla y a pesar de ser criticada con dureza por Ortega y Rubio ${ }^{59}$, dejaba de ser protagonista para convertirse en lo que desde un principio pudo ser: un elemento funcional que transgrediera lo menos posible los límites arquitectónicos de la iglesia. La sustitución de la espadaña contraviene las ideas de Boito ${ }^{60}$, que critican la unidad de estilo violletiana en favor de la riqueza histórica y arquitectónica del edificio (Martínez et al., 2008, p. 241). Así, Ortiz de Urbina diseñó un sencillo murete rectangular sobre el que se dibujan dos arcos de medio punto rematados por un piñón. Por tanto, como la sacristía, la espadaña era un elemento absolutamente funcional. Para su construcción, Ortiz de Urbina siguió el estilo general del edificio ${ }^{61}$. Es decir, nuevamente en la línea de lo preceptuado por la Real Orden de 14 de septiembre de 1950 y la "restauración en estilo" de Viollet-le-Duc. En este último caso, como ya se ha dicho, eliminando un elemento ajeno en origen, sustituyendo el ladrillo por la piedra del resto del edificio y adaptando la estructura a la estética románica.

Las obras fueron numerosas en el interior. Si todavía hubiera dudas sobre la existencia, desde un principio, o no, de cubierta abovedada ${ }^{62}$, el informe ofrece datos contundentes, al menos respecto a lo que Ortiz de Urbina se había encontrado. Según este, se volteó "una bóveda tabicada, de que carecía, asegurando y reparando completamente la que cubría el presbiterio, la cual es de piedra". Para ello, Ortiz de Urbina manejó ladrillo revestido de yeso puro. Afirmaba, además, que en la "fuerte armadura" - de madera de pino de Soria - que había diseñado para apoyar la bóveda, y en la que introdujo seis tirantes de hierro ${ }^{63}$, se había tenido en cuenta tanto la altura del edificio como aquella que habría de ganar con el objeto de no disminuir el espacio interior y "evitar los empujes laterales sobre los muros". Como vemos, Ortiz

59 Ortega y Rubio lamentaba el poco gusto que se había tenido en los detalles del edificio y en la construcción de la espadaña (Ortega, 1895, p. 177).

60 Los principios de la llamada "restauración científica" se encuentran en Boito, Camilo (1893). Questioni pratiche di Belle Arti. Restauri, concorsi, legislazione, proffesione, insegnamento. Milano: Ulrico Hoepli, editore-libraio della Real Casa. Disponible en: https://archive.org/details/ questionipratich00boit/page/n6

61 La relación de la imagen de la espadaña con la de otras románicas es evidente. Cabe citar la de Santa Eulalia de Ques (Piloña, Palencia) o la más espectacular, salvando las distancias, de la colegiata de San Salvador de Cantamuda (Palencia).

62 Lampérez y Romea señalaba que la iglesia había poseído una cubierta de madera, siendo el ábside abovedado (Lampérez, 1930, tomo II, p. 106). Aunque González Tejerina abogaba por la existencia originaria de una cubrición abovedada, Heras García razona hasta llegar a la misma conclusión de Lámperez y Romea. Además, afirma, con tino, que la bóveda sería obra de la restauración practicada en 1876 (González, 1932 - 1933, p. 248; Heras, 1966, p. 68).

63 Base octava de las condiciones facultativas y económicas de las obras. 2 de junio de 1875, ACVA, RTC, legajo 1837 - 1861, exp. 22. 
de Urbina no utilizó ni los elementos estructurales ni los materiales ya presentes en la iglesia.

Existen, así, demasiados indicios que llevan a pensar, como Lampérez y Romea, Heras García y otros investigadores, que la iglesia no habría sido abovedada en origen. Pero, ¿por qué Ortiz de Urbina optó por la solución abovedada cuando lo que se había encontrado en la iglesia era una techumbre de madera? ¿Es posible que llegara a pensar en la existencia de una solución abovedada en origen? Con aquella decisión Ortiz de Urbina modificó, sustancialmente, la realidad encontrada, reinventando, a su modo de ver, la arquitectura. ¿Por qué una bóveda era mejor solución para la iglesia que una cubierta de madera? Quizá la elección responda al deseo de incluir en el edificio los elementos más característicos, según su parecer, de la arquitectura románica, dotándole de una mayor fortaleza histórica y artística y devolviéndole una hipotética imagen original, o no. Así, el trabajo de Ortiz de Urbina emparentaba con el pensamiento violletiano, que trató el tema del abovedamiento en el Románico como el ensayo que precedía al gran momento del Gótico ${ }^{64}$. Y es que cuando Ortiz de Urbina llevó a cabo ejemplos neogóticos o neorrománicos de nueva planta casi siempre procuró dotar al edificio de las características, en muchas ocasiones reinventadas, que configuraron cada uno de los estilos que, en un principio, podrían haber inspirado aquellas obras. Tal es el caso de la iglesia de la Sagrada Familia (Valladolid, 1898 - 1899), cuyo aspecto neorrománico se veía refrendado, entre otros elementos, por la bóveda de cañón que cubría su única nave (González, 1900: p. 140; Ortega, 2000: 228). En este sentido, al tratarse de una obra de nueva planta, la libre acción del arquitecto permitió la introducción de contrafuertes para ayudar a la composición de la bóveda. Por el contrario, en Arroyo los contrafuertes no existían. Su falta podía representar una clara limitación para Ortiz de Urbina a la hora de acercarse a la configuración de un pequeño templo románico ideal. Sin embargo, los avances técnicos en arquitectura permitieron que los deseos del arquitecto restaurador primaran sobre las hipotéticas "carencias" - ahora sabemos que falsas - del edificio. La inclusión de contrafuertes no hubiera tenido sentido y, al mismo tiempo, no sabemos si conscientemente por parte de Ortiz de Urbina, seguía el ideario de Viollet, dado que la aplicación de una serie de principios absolutos en restauración podría conducir a lo absurdo (Viollet, 1866, p. 24). De esta manera, toda la iglesia pudo presentarse abovedada, a la vez que se demostraba lo que en León Demetrio de los Ríos denominó "proyectos de reconstrucción", "opinables", "discutibles" y de clara invención desde el punto de vista artístico y arqueológico (González - Varas, 1993, p. 299; 1996, p. 59). Así, en relación con Viollet, Ortiz de Urbina propone la idea de mejorar la obra a partir de la unidad alcanzada en el edificio. Desde el punto de vista de la conciliación de las instancias histórica

64 Recordamos la cita de Viollet - le - Duc en su artículo Construction del Dictionnaire raisonnée de l'architecture française du XIe au XVIe siècle: "Évêques, moines, seigneurs, bourgeois, l'eussent ils voulu, n'auraient pu empêcher l'architecture romane deproduire l'architecture dite gothique: celle-ci n'était que la conséquence fatale dela première" (Viollet, 1854, p. 21). 


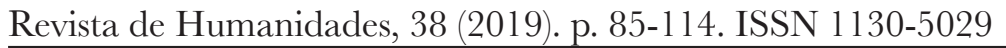

y estética, se incluye la proyección de una nueva bóveda en un ejemplo de estilo "bizantino puro", el "único [...] que permanece en esta provincia de los Templarios", tal y como ya se ha visto. En todo caso, esto mismo también demuestra un evidente desconocimiento por parte de Ortiz de Urbina acerca del edificio, apoyándose en cuestiones estéticas genéricas que en ningún caso defiende Viollet. De igual forma, es interesante la introducción de tirantes de hierro, esto último, como nuevo material, sí aceptado por el arquitecto francés (Viollet, 1866, p. 32).

Ortiz de Urbina construyó un funcional pero incoherente coro que apea sobre dos pares de columnillas bajo unos desacertados diseños neorrománicos ${ }^{65}$ (fig. 11), así como una escalera de caracol para servicio de este y de la espadaña. También abrió una hornacina en la pared norte de la iglesia para instalar la pila bautismal. De nueva planta diseñó una sacristía, que sigue, como siempre según Ortiz de Urbina, la línea estilística de la iglesia. Por tanto, el arquitecto cuidó el destino del edificio, satisfaciendo las necesidades exigidas por la función o el destino del mismo, según el pensamiento de Viollet. Al mismo tiempo, Ortiz de Urbina mantuvo en la sacristía la escala relativa al conjunto tan defendida por el arquitecto francés en las construcciones medievales (Viollet, 1866, pp. 26 y 31). Por último, con la restauración también se entarimó el templo, al mismo tiempo que se rebajó el terreno de la parte sur, saneando el interior.

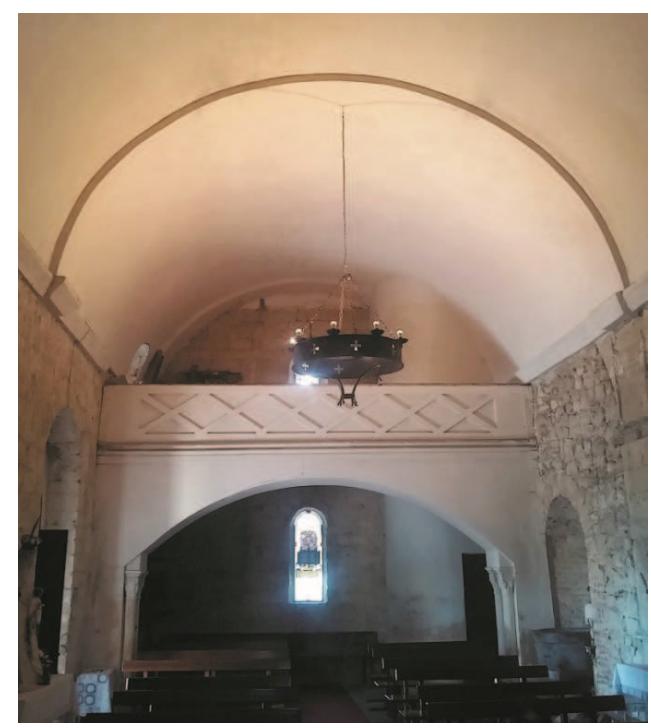

Figura 11. Estado actual del coro y bóveda tabicada de la iglesia. Elaboración del autor.

65 Según las condiciones facultativas, Ortiz de Urbina también aquí había pensado introducir hierro, con lo que nuevamente se acercaría al ideario violletiano. Aunque finalmente no fue así, la idea original era incluir dos columnillas de hierro que soportaran, en la zona central, la carrera del atirantado de madera empotrada en los muros. ACVA, RTC, legajo 1837 - 1861, exp. 22, 2 de junio de 1875. 
El informe señala cómo el Conde de Guaqui había aportado una importante suma de dinero que fue utilizada para vestir la iglesia. Para la sacristía se compró una mesa y una cajonería, se instaló un nuevo púlpito y una verja para el presbiterio, a la vez que se fundió una nueva campana, "por hallarse rota una de las dos que tenía la espadaña".

Analizada la restauración desde diversos puntos de vista, parece claro que Ortiz de Urbina se basó, fundamentalmente, en la teoría orgánica de la restauración arquitectónica, aquella que llamamos "restauración estilística". Propugnada por Viollet-le-Duc, Académico Honorario de San Fernando desde 1868 Urbina coincidía en la redacción de su informe con ciertos postulados violletianos ya expuestos en la voz "Restauration" del Dictionnaire raisonné de l'architecture française du XI au XVI siécle. De hecho, debemos tener en cuenta que la Real Orden de 14 de septiembre de 1850 ya exigía, entre otras cosas, el respeto en las fachadas del "pensamiento primitivo, acomodando las renovaciones al carácter de la fábrica, y procurando que las partes antiguas y las modernas se asemejen y parezcan de una misma época" (Boletín Oficial del Ministerio de Hacienda, 1850, pp. 466 y 467; De la Cámara, 1871, p. 214; Navascués, 1987, p. 293). De igual forma, no se permitía variación en la decoración (Boletín Oficial del Ministerio de Hacienda, 1850, p. 466). Sin duda, así actuó Ortiz de Urbina, aunque aquellos actos de "invención depurada" que dominaban las ideas de Viollet-le-Duc no fueron tan evidentes en el trabajo del arquitecto español, prefiriendo, sobre todo, copiar lo que ya había. Así, citamos la nueva elaboración de ménsulas que repetían motivos presentes en las antiguas, y todavía conservadas, o los diseños casi calcados de capiteles de origen vegetal, sin instrumentalización de la materia con una carga simbólica de originalidad. Esta fue su opción, alejándose de la misma en la proyección del coro a los pies. Aquí, cabe citar un informe, firmado por Ortiz de Urbina, Iturralde y Rezola, en 1878, respecto a la reparación y restauración de la zona de soportales del centro histórico de Valladolid, donde queda claro tanto la influencia de Viollet como de la más cercana y citada disposición de 14 de septiembre de 1850 en torno a restauración arquitectónica: "Es un principio en el Arte, que cuando se trata de restaurar un Monumento, la restauración será tanto mejor cuanto menos se descubra la mano del restaurador" (Rebollo, 2007, p. 1263).

Como también defendía Viollet-le-Duc, nada debía dejarse a la improvisación, pese a que en el transcurso de las obras se modificase el proyecto inicial. Así fue: existen informes, memorias de los trabajos a ejecutar, presupuestos que detallaban las obras que se pensaban llevar a cabo, etc. De lo que no cabe duda es de que a partir del fragmento, y mediante el principio de analogía, se lograba la reconstrucción total del edificio. Esa fue la vía elegida por Ortiz de Urbina. Es más, el cultivo de la

66 En numerosas publicaciones se ha tratado el nombramiento de Viollet-le-Duc como Académico Honorario de San Fernando. Una propuesta que aceptó el arquitecto francés a través de la remisión de una carta el 21 de junio de 1868 (González - Varas, 1996, p. 48). 


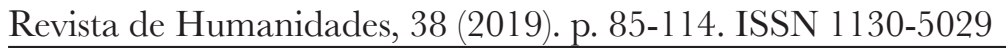

corriente violletiana en las restauraciones practicadas por un círculo de amigos de Ortiz de Urbina también es patente. Es el caso de los arquitectos Juan de Madrazo y, sobre todo, Adolfo Fernández de Casanova (Domínguez, 2010, pp. 26 y 32), que durante el desempeño del cargo de Arquitecto Provincial de Valladolid, en fechas previas al inicio de la restauración, pudo influir en los ideales violletianos puestos en práctica por Ortiz de Urbina ${ }^{67}$. Algunas de sus ideas ya se esbozan en Arroyo de la Encomienda, aunque siempre en consideración a un hecho absolutamente funcional y a veces alejado de conceptos teóricos. Lo que parece claro es que en nuestro arquitecto, condiscípulo también de Elías Rogent, Francisco de Cubas, Demetrio de los Ríos o Francisco de Paula del Villar Lozano en la Escuela Especial de Arquitectura de Madrid, existe una tendencia neomedievalista que, como señala González - Varas respecto a las primeras promociones de la escuela, se aprecia tanto en la creación arquitectónica como en la "restauración de monumentos en estilo" (González - Varas, 1996, p. 56). Por tanto, en aquel trabajo apreciamos no tan descabelladas decisiones como la historiografía ha querido ver durante años. Cierto es que la práctica restauradora del siglo XIX se diferenciaba de la anterior en la valoración previa y justificadora del monumento arquitectónico en sí, de su propia condición histórica y como valor cultural, no de su aspecto funcional ${ }^{68}$. En los informes de Ortiz de Urbina y Rezola también sucedía esto. Para ellos, la iglesia era un ejemplo de estilo "bizantino puro" y, por ende, de especial mérito artístico. Sin embargo, en todo momento la documentación también reclama el especial interés del mantenimiento de la funcionalidad del edificio, otra idea violletiana. Su reapertura al culto era una prioridad, puesto que esto mismo ayudaba, según Ortiz de Urbina, a la conservación de su arquitectura. De hecho, los trabajos de restauración llevados a cabo por el arquitecto vitoriano siempre englobaron dos cuestiones: funcionalidad y estilo (Domínguez, 2013, p. 40).

Para finalizar, en marzo de 1889 el Ayuntamiento de Arroyo expresaba su deseo de que el antiguo cementerio de la población, contiguo a la iglesia de San Juan, desapareciese "en atención á las pésimas condiciones higiénicas del mismo y á los perjuicios que ocasionaba en las fábricas de tan rica y reconocida joya artística a tanta costa restaurada" ${ }^{69}$. No cabe duda de que Ortiz de Urbina fue el primero en proponer la desaparición, puesto que antes de que se publicase la subasta de las obras de la iglesia ya había transmitido la posibilidad de que se trasladara el antiguo camposanto

67 Investigadores como González - Varas no dudan en presentar los trabajos de restauración llevados a cabo por Fernández Casanova en la catedral de Sevilla "en clara deuda con el concepto de restauración formulado por Viollet - le - Duc" (González - Varas, 1994, p. 105).

68 Navascués ejemplifica esto mismo comparando las restauraciones que del acueducto de Segovia se habían llevado a cabo en los siglos XV y XVIII y la practicada en el XIX, esta última ya no con intención de hacer que el acueducto cumpliese con su tarea mecánica, sino que sirviese de representante de una cultura determinada (Navascués, 1987, p. 288).

69 AHPVA, SH, caja 271, legajo 9, exp. 92, 23 de marzo de 1889. 
a un nuevo emplazamiento ${ }^{70}$. La propia Comisión Provincial de Monumentos, tras visitar el templo, apoyó la propuesta, ofreciendo toda su ayuda para llevarla a cabo ${ }^{71}$.

\section{CONGLUSIONES}

Propio de la época, el creciente interés en la defensa de monumentos y obras artísticas tendría en Valladolid como principal baluarte a su Comisión Provincial de Monumentos. Sus integrantes: pintores, escultores o arquitectos, entre ellos Ortiz de Urbina, intentaron, dentro de sus posibilidades y en continua negociación con otras corporaciones de las que dependían, la conservación, en el ámbito arquitectónico, del mayor número de edificios de interés histórico y artístico. Entre ellos, la iglesia románica de San Juan Ante Portam Latinam, en torno a la cual se generó un expediente con entidad propia y numerosa documentación, casi al nivel de otros trabajos de conservación y restauración de monumentos tan importantes como la vallisoletana iglesia del convento de San Benito o el antiguo colegio de Santa Cruz. La lenta burocracia, los problemas de financiación o el frágil apoyo institucional, algo común a otros casos españoles de la época, fueron los principales motivos por lo que las obras en el templo arroyano tardaron más de una década en dar inicio.

En la restauración, el arquitecto vitoriano tomó como base de su trabajo la doctrina violletiana tan arraigada en la cultura restauradora española a mediados del siglo XIX y que tuvo entre sus protagonistas a sus condiscípulos, en la Escuela Especial de Arquitectura de Madrid, Demetrio de los Ríos y Juan de Madrazo. Cuestiones desarrolladas por estos últimos, por ejemplo, en la Catedral de León, fueron tenidas en cuenta por Ortiz de Urbina en la iglesia templaria de Arroyo de la Encomienda, su proyecto más personal dentro del campo de la restauración. En cierto modo, también la comprobada relación de amistad que mantuvo con Adolfo Fernández de Casanova, arquitecto restaurador de la Catedral de Sevilla, refuerza la lógica adopción de estas ideas. Sobre esta base, Ortiz de Urbina aplicó e interpretó lo preceptuado por la Real Orden de 14 de septiembre de 1850, derivando sus decisiones, en cuestiones puntuales, hacia ideas que pocos años después defendería Camilo Boito en el III Congreso de Ingenieros y Arquitectos italianos (Roma, 1883). En todo caso, la complejidad conceptual en el proyecto de restauración de San Juan Ante Portam Latinam es tal que, como se puede comprobar, en él convergen diferentes ideas, posturas y teorías desarrolladas durante el siglo XIX. El estudio de esto mismo lo facilita el conocimiento del estado del templo, antes de la intervención, que proporcionan las cuatro fotografias, hasta ahora inéditas, tomadas en 1867 y que

70 El Alcalde confirmaba que desde hacía cinco años en el antiguo cementerio no se habían realizado inhumaciones. El motivo no sería otro que la existencia de "un cementerio de nueva y sólida construcción á distancia conveniente del pueblo”. ACVA, RTC, legajo 1837 - 1861, exp. 22, 7 de agosto de 1875 .

71 AHPVA, SH, caja 271, legajo 9, exp. 93, 15 de abril de 1889. 


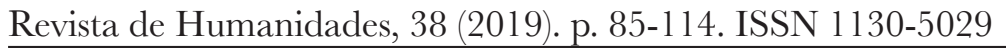

se conservan en el archivo de la Real Academia de Bellas Artes de San Fernando (Madrid). Por tanto, la fotografía no solo sirve de fuente primaria para realizar el análisis del trabajo llevado a cabo por el arquitecto restaurador, sino también, en su día, sirvió como testigo y prueba del estado de la iglesia en sus puntos más importantes según los miembros de la Comisión Provincial de Monumentos encargados, en su momento, de reflejar e informar sobre las necesidades de la fábrica.

\section{BIBLIOGRAFÍA}

Boletín Oficial del Ministerio de Hacienda (10 de octubre de 1850). Real órden dictando las reglas que han de observarse cuando por efecto de la de 3 de Julio último, relativa á la cesión de edificios que lo estaban á cargo de la Comisión Central de Monumentos históricos y artísticos, se haya de hacer alguna variación en la planta ú ornamentación de los mismos, por las corporaciones ó particulares á quienes les sean cedidos. En BOMEH, tomo II, n 41, pp. 466 y 467.

Calatrava, Juan Antonio (1995). La visión de la historia de la arquitectura española en las revistas románticas. En VII Jornadas de Arte. Historiografia del Arte español en los siglos XIX y XX. Madrid: Alpuerto Ediciones, pp. 53-62.

De Cossío, Francisco (1922). Guía-anuario de Valladolid y su provincia. Valladolid: Casa Santarén.

De la Cámara, Eugenio (1868). Resumen de las Actas y Tareas de la Real Academia de Nobles Artes de San Fernando durante el año académico de 1867 á 1868. Madrid: Imprenta de Manuel Tello.

De la Cámara, Marcial (1871). Tratado teórico-práctico de Agrimensura y Arquitectura Legal. Valladolid: Imprenta y Librería Nacional y Extranjera de Hijos de Rodríguez. Disponible en: http://bibliotecadigital.jcyl.es/es/catalogo_imagenes/ grupo.cmd?path $=10066278$

De los Ríos, Demetrio (1895). La catedral de León (tomo II). Madrid: Imp. del Sagrado Corazón de Jesús. Disponible en: https://bibliotecadigital.jcyl.es/es/catalogo_ imagenes/grupo.cmd?path $=10076870$

Domínguez, Francisco Javier (2010). El Valladolid de los Ortiz de Urbina: arquitectura y urbanismo en Valladolid (1852-1936). Valladolid: Ayuntamiento de Valladolid.

Domínguez, Francisco Javier (2013). La Junta Diocesana de Obras y Reparaciones, el Puebloy el Estado durante la segunda mitad del siglo XIX: Proyectos de conservación, restauración y de nueva planta en la arquitectura religiosa vallisoletana de Jerónimo Ortiz de Urbina. En ACE: Architecture, City and Environment [en línea], n. 21, pp. 37-66. Disponible en https://upcommons.upc.edu/handle/2099/13007

Fernández, María Antonia (1981). Desarrollo urbano y proceso histórico del Campo Grande de Valladolid. Valladolid: Ayuntamiento de Valladolid.

García, José Enrique (1988). La visión del Románico en la historiografía española del «Neoclasicismo romántico». En Revista de la Facultad de Geografía e Historia, n. 2, pp. 139-186. 
Criterios prácticos de restauración arquitectónica... - F.J. Domínguez Burrieza

González, Casimiro (1900). Valladolid. Sus recuerdos y sus grandezas: Religión, Historia, Ciencias, Literatura, Industria, Comercio y Política (tomo I). Valladolid: Imp. de Juan Rodríguez Hernando.

González, Mercedes (1932-1933). Papeletas de Arte Románico castellano. La iglesia de San Juan, de Arroyo de la Encomienda. En B.S.A.A., n. 1 (III), pp. 247-252.

González - Varas, Ignacio (1993). La catedral de León: Historia y restauración (18591901). León: Universidad de León.

González - Varas, Ignacio (1994). La catedral de Sevilla (1881-1900): el debate sobre la restauración monumental. Sevilla: Diputación Provincial de Sevilla.

González - Varas, Ignacio (1996). Restauración monumental en España durante el siglo $X I X$. Valladolid: Colegio Oficial de Arquitectos de León.

Heras, Felipe (1966). Arquitectura románica en la provincia de Valladolid. Valladolid: Imprenta Provincial.

Herrero, Jesús (1997). Arquitectura y simbolismo del Románico en Valladolid. Madrid: Ars Magna Ediciones.

Iturralde, Fernando (1904). Excursión a Arroyo, Simancas y Tordesillas (26 de junio de 1904). En Boletín de la Sociedad Castellana de Excursiones, n. 20, pp. 365-371.

Lampérez, Vicente (1930). Historia de la arquitectura cristiana española en la Edad Media, según el estudio de los elementos y los monumentos (tomo II). Madrid: Espasa - Calpe.

Lázaro, Juan Bautista (1884). El criterio artístico. En Revista de la Sociedad Central de Arquitectos, n. 10, pp. 193 y 194.

Martín, Juan José (dir.) (1970). Inventario artístico de Valladolid y su provincia. Valladolid y Madrid: Dirección General de Bellas Artes.

Martínez, M $\mathrm{M}^{\mathrm{a}}$ José et al. (2008). Historia y teoría de la conservación y restauración artística (tercera edición). Madrid: Editorial Tecnos.

Navascués, Pedro (1987). La restauración monumental como proceso histórico: El caso español, 1800 - 1950. En Bustos, Carlos (dir.). Curso de Mecánica y Tecnología de los edificios antiguos. Madrid: Colegio Oficial de Arquitectos de Madrid, pp. 285-329.

Olivera, María del Rosario y Ruiz, Fulgencio (2002). Arroyo de la Encomienda. Iglesia de San Juan ante Portam Latinam. En García, Miguel Ángel y Pérez, José María (dirs.). Enciclopedia del Románico en Castilla y León. Valladolid. Aguilar de Campoo: Fundación Santa María la Real Centro de Estudios del Románico, pp. 103-112.

Ordieres, Isabel (1995). Historia de la Restauración Monumental en España (18351936). Madrid: Instituto de Conservación y Restauración de Bienes Culturales.

Ortega, José (1895). Los pueblos de la provincia de Valladolid. Valladolid: Diputación Provincial de Valladolid. 
Revista de Humanidades, 38 (2019). p. 85-114. ISSN 1130-5029

Panadero, Nieves (1997). La definición del estilo románico en la historiografía española del romanticismo. En Anales de Historia del Arte, n. 7, pp. 245-256. Disponible en: https://revistas.ucm.es/index.php/ANHA/article/view/ANHA9797110245A/31605

Pérez, Joaquín (1932-1933). Excursiones realizadas durante el primer trimestre del curso actual por el Seminario de Estudios de Arte y Arqueología de la Facultad de Historia. En B.S.A.A., n. 1 (I), pp. 12-15.

Quadrado, José María / Parcerisa, Francisco Javier (1861). Recuerdos y bellezas de España...Valladolid, Palencia y Zamora. Barcelona: Imp. de Joaquín Verdaguer.

Rebollo, Alejandro (2007). En defensa de la conservación del conjunto soportalado de la Plaza Mayor de Valladolid: la respuesta de modificación de las Ordenanzas Municipales en 1878. En Rivera, Javier (dir.). Actas del V Congreso Internacional "Restaurar la memoria. Patrimonio y Territorio". Valladolid: Junta de Castilla y León yAR@PA, pp. 1259-1273.

Viollet - le - Duc, Eugène - Emmanuel (1854). Dictionnaire raisonnée de l'architecture française du XI au XVI siècle (tomo IV). Paris: B. Bance Éditeur. Disponible en: https://fr.wikisource.org/wiki/Livre:Viollet-le-Duc_Dictionnaire_ raisonn $\%$ C3\%A9_de_1\%E2\%80\%99architecture_fran\%C3\%A7aise_du_XIe_au_ XVIe_si\%C3\%A8cle,_1854-1868,_tome_4.djvu

Viollet - le - Duc, Eugène - Emmanuel (1866). Dictionnaire raisonnée de l'architecture française du XI au XVI e siècle (tomo VIII). Paris: A. Morel. Disponible en: https:// fr.wikisource.org/wiki/Livre:Viollet-le-Duc_-Dictionnaire_raisonn\%C3\%A9

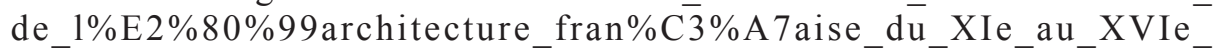
si\%C3\%A8cle,_1854-1868,_tome_8.djvu 